\title{
Rethinking an Admissions Program to Align with the Mission of an Innovative Medical School
}

\author{
Joel A. Daboub ${ }^{1}$. Andrew D. Bergemann ${ }^{1}$ (D) - Stephen R. Smith ${ }^{1}$ \\ Accepted: 21 September 2020 / Published online: 8 October 2020 \\ (C) International Association of Medical Science Educators 2020
}

The formation of a new medical school creates unique challenges and opportunities. This was true at our school with its mission that is strongly oriented to leadership as a competency. Similar to most schools utilizing holistic admissions policies, we wanted to identify and matriculate applicants with a wide range of skills and attributes that are not necessarily linked to academics [1]. However, because of our unique mission, we wanted to place a particular focus on leadership, innovation and creativity, and community engagement [2], when selecting applicants. Therefore, we developed a combination of traditional and novel approaches, including a number of significant innovations that focus on mission-relevant attitudes and attributes. In line with the school's values of selfreflection and adaptability, we have actively engaged in the evaluation of innovations and modified our initial design in response to observed outcomes.

Each applicant initiated their candidacy for our school by completion of the Texas Medical and Dental School Application Process (TMDSAS) application, an approximate parallel to the American Medical College Application Service (AMCAS) used in most states [3]. We prescribed fewer pre-requisite courses than many other US medical schools in order to facilitate applications from students with more diverse educational and professional backgrounds. We designed a secondary application that specifically asked applicants to describe their life experiences related to leadership, innovation and creativity, and community engagement. In 2018 , we changed this secondary application to an asynchronous video format, but still asked for life experiences in those same three domains (see Fig. 1).

Andrew D. Bergemann

andrew.bergemann@austin.utexas.edu

1 Department of Medical Education, Dell Medical School, University of Texas at Austin, 1501 Red River Street, Austin, TX 78712, USA
Based upon the reviews of the applications and the ratings of the video interviews, students were selected for an on-site interview. Interview day comprised of a classical interview, a group task (which will be described in detail below), and five multiple mini-interview (MMI) stations. When all the assessment tools were completed, the Admissions Selection Committee (ASC) reviewed each interviewed applicant utilizing over 60 individual points of evaluation. These points of evaluation were generated from the reviews of each applicant's original application and the ratings of their interviews.

The components of our process that we regard as the most innovative are the addition of a group task to interview day and using video interviews to pre-screen applicants. Other noteworthy components included our removal of letters of recommendation from initial consideration, our use of diverse sources of raters for applicant assessments, our tailoring the rating criteria used by interviewers to correlate with missionaligned attributes and skills, and our use of a heatmap to present the accumulated data for each applicant to the final decision-makers (the members of the ASC).

\section{Innovations to the Process for Selecting Candidates for On-site Interviews}

For all applicants submitting for admission (approximately 5000 per year), each TMDSAS application underwent an initial review to identify approximately 700 applicants with selfreported experiences that align with the school's mission. This initial screen emphasized each applicant's experiences above academic performance. Furthermore, we instructed raters to view an upward momentum of academic performance through the college years very positively. We invited applicants chosen in this initial screen to complete a school-specific secondary application. For the 2016 and 2017 matriculating classes, the secondary application composed of four additional essays, emphasizing the school's priorities. For the 2018 and 2019 matriculating classes, we replaced the secondary essays with 
Fig. 1 Outline of our admissions process. LORS, letters of recommendation; ASC, Admissions Selection Committee

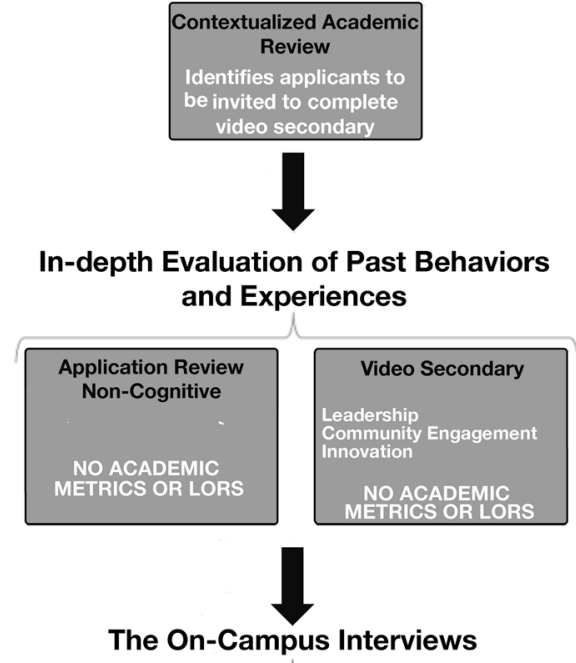

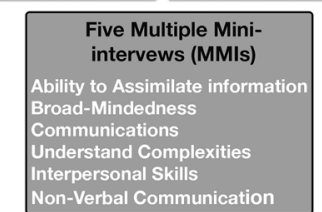

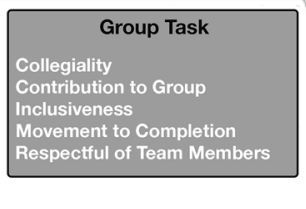

\begin{tabular}{|l|}
\hline $\begin{array}{l}25 \text { Minute Traditional } \\
\text { Interview }\end{array}$ \\
Assessment of \\
Unique Contributions
\end{tabular}

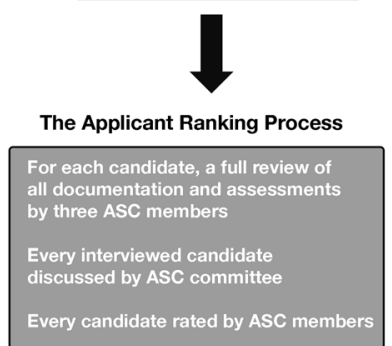

video interviews asking candidates to reflect upon their experiences in leadership, innovation, and community engagement.

The video interviews were tightly electronically secured, asynchronous, and timed. They allowed interviewees to answer the questions at the time of their choice and on the device of their choice. However, once they began their response, they had to complete each question within a two-minute window. Additionally, they had only one opportunity to answer the question to create the nearest analog to an in-person interview as possible.

The asynchronous nature of the application platform similarly allowed the rater to choose when and where to review the videos, which could be re-watched as many times as needed. The video interviews allowed for an initial assessment of student's ability to communicate a narrative in a defined window of time, much like a traditional MMI, and to describe past behavior in the desired dimensions of innovation and creativity, leadership, and community engagement, in a manner that reduced consumption of both the school's and the applicant's resources. As we approach a very special admissions season, where on-site interviews are unlikely to occur, we will adapt the video capabilities we have developed to be our primary interview venues.

For each applicant completing the secondary (essays or video), we assigned two reviewers to complete a detailed review of their TMDSAS application. From 2017 onwards, these reviewers were blinded to the student's academic performance. This reflected both well-known biases created by academic performance and our belief that academic metrics are not the best way to identify physician leaders [4]. From 2018 onwards, we also blinded reviewers to letters of recommendation, because of our observation that these created similar influence on rater evaluations, as many letters of recommendation highlight specific academic performance metrics. The results of these reviews, combined with the results of the rater assessments of video interviews, determined whether we invited an applicant for an on-site interview at the school.

\section{Innovations Changing Our Interview Day}

Each applicant invited to an interview day was rated on their performance in eight (2016 and 2017) or seven (2018 and 
2019) interviews or tasks. For the first two years, applicants had two one-on-one interviews, the traditional staple at medical schools. We dropped the number of traditional interviews to one per student after the first two years, as we found limited additional information from the second interview (data not shown). Throughout, we also used five multiple miniinterviews (MMIs), like those described elsewhere $[5,6]$. Our Admissions Selection Committee (ASC) wrote and approved each MMI scenario with the intent of addressing a specific desired attribute.

We used the group task to assess each applicant's teamwork skills. We assigned candidates to groups of five, and each group was assigned a task to perform, while being observed by a single rater. While the task set varied from year to year, all applicants within a given academic year were assigned the same task. A typical task was to ask the students to act as an advisory board. They were then provided a list of valuable community projects, each project with a predetermined cost. The final component of the task was that the advisory board was not provided sufficient funds to complete all the projects, and therefore, as a team they had to choose the projects to be funded. Clearly, we were not seeking a particular correct answer, but instead we were interested in each applicant's contributions to the process of developing the group's answer. As such, we asked raters to evaluate applicant performance using five, six-point Likert scales, assessing team-related behaviors and skills. With all our evaluation processes, we considered rater training a key component of success. We recruited group task (and MMI) raters from a wide swath of our community, including undergraduate faculty, medical school faculty, medical school staff, senior medical students, and community physicians.

\section{Innovations Introduced into Our Final Ranking Process}

We accumulated all the data from assessments, both qualitative and quantitative, for each student in a single file. The quantitative data was presented as a heatmap, with red reflecting weaker scores and green reflecting stronger scores. In this file, we also provided derived quantitative measures of the student's communication skills, aptitudes, and experiences. This file, along with the original TMDSAS application, was supplied to three members of the ASC for detailed review. These three members provided an initial evaluation of the applicant, and then briefed the committee as a whole. The committee as a whole then voted on each applicant, generating a qualitative assessment of the applicant that was used for ranking purposes.

\section{Survey Results}

Each year, the American Association of Medical Colleges (AAMC) asks the matriculants of all the nation's medical schools to complete the "Matriculating Student Questionnaire" (MSQ). The MSQ is composed of 45 questions addressing a wide range of student concerns and interests. In Q32, the MSQ asks students to rate the importance to their career of a range of motivators. Among the motivators are a number that are mission-relevant for us, namely opportunities for leadership potential (LP), opportunities for innovation (OI), working for social change (SC), and creativity and initiative (CI). Also included in Q32 are a number of motivators that are not as specifically tied to the uniqueness of our mission, namely personal values (PV), high income potential (IP), social recognition or status (SR), secure future (SF), availability of jobs (AJ), work/life balance (WL), and ability to pay off debt (PD). For each motivator, matriculating students are asked to choose from a Likert scale, anchored as "not important," "somewhat important," "very important," and "essential." We used the MSQ data to determine whether our admissions program successfully recruited students who self-identified as having priorities consistent with our mission. As the investigators received the MSQ data aggregated and de-identified, and there was no mechanism for re-identification, Institutional Review Board (IRB) evaluation was deemed unnecessary for this study.

A larger proportion of the school's matriculants (20162019) rated each of the mission-relevant motivators as essential than did matriculants nationally (effect size ratios: LP: $1.40, p<0.05$; OI: $1.64, p<0.001$; CI: $1.51, p<0.005$; SC: $1.45, p<0.005$ ) (Table 1 and Fig. 2). For each of these mission-relevant motivators, the effect was statistically significant. Hence, through our process, we identified and recruited applicants who have priorities consistent with the school's mission. For most of the motivators that are not mission-relevant, our matriculants were less likely to prioritize each motivator as essential than their peers (effect size ratios PV: 1.23 , not significant: IP:0.36, not significant; SR: 0.43 , not significant; SF: 0.74, $p<0.05$; AJ: 0.69, not significant; WL: 0.84, not significant; PD: $0.6, p<0.001$ ).

Among the four motivations that we prioritize, the priorities of our matriculants have been relatively consistent across the four years. Trendlines across the four years have the following gradients (expressed in units of change in percent rating "essential" per annum): leadership: $0.45 \%$; innovation: $-0.31 \%$; social change: $-3.19 \%$; creativity: $-3.05 \%$. None of the changes was substantial enough to reject the null hypothesis that our program is recruiting matriculants with the desired priorities with the same efficiency across the years. Interestingly, matriculants nationally are increasingly likely to view these motivators as essential (Fig. 2). 
Table 1 Cumulated numbers considering each motivator as essential over the four years of the study. Data can be downloaded from 10.6084/ m9.figshare. 12354692

\begin{tabular}{|c|c|c|c|c|c|c|c|c|}
\hline Motivator & $\begin{array}{l}\text { DMS } \\
\text { respondents } \\
\text { total }\end{array}$ & $\begin{array}{l}\text { DMS total } \\
\text { ranking } \\
\text { essential }\end{array}$ & $\begin{array}{l}\text { All other } \\
\text { schools total } \\
\text { respondents }\end{array}$ & $\begin{array}{l}\text { All other schools } \\
\text { total ranking } \\
\text { essential }\end{array}$ & $\begin{array}{l}\text { DMS } \\
\text { percentage } \\
\text { ranking } \\
\text { essentials }\end{array}$ & $\begin{array}{l}\text { All other schools } \\
\text { percentage ranking } \\
\text { essential }\end{array}$ & $\begin{array}{l}\text { Effects } \\
\text { size }\end{array}$ & $\begin{array}{l}\text { Chi-squared } \\
(p)\end{array}$ \\
\hline Leadership & 196 & 60 & 52,912 & 11,596 & 30.6 & 21.9 & 1.40 & 0.035 \\
\hline Innovation & 196 & 74 & 52,867 & 12,196 & 37.8 & 23.1 & 1.64 & 0.000 \\
\hline Creativity & 196 & 65 & 52,891 & 11,602 & 33.1 & 21.9 & 1.51 & 0.003 \\
\hline Social change & 196 & 72 & 52,949 & 13,402 & 36.7 & 25.3 & 1.45 & 0.004 \\
\hline $\begin{array}{r}\text { Personal } \\
\text { values }\end{array}$ & 194 & 74 & 52,915 & 16,376 & 38.2 & 30.9 & 1.23 & 0.194 \\
\hline $\begin{array}{l}\text { Income } \\
\text { potential }\end{array}$ & 196 & 4 & 52,944 & 3016 & 2.0 & 5.7 & 0.36 & 0.182 \\
\hline Social status & 196 & 2 & 52,907 & 1244 & 1.0 & 2.4 & 0.43 & 0.677 \\
\hline Secure future & 196 & 63 & 52,984 & 22,877 & 32.1 & 43.1 & 0.74 & 0.021 \\
\hline Job availability & 196 & 32 & 52,953 & 12,474 & 16.3 & 23.6 & 0.69 & 0.129 \\
\hline $\begin{array}{l}\text { Work/life } \\
\text { balance }\end{array}$ & 196 & 79 & 52,962 & 25,420 & 40.3 & 48.0 & 0.84 & 0.200 \\
\hline $\begin{array}{l}\text { Debt } \\
\quad \text { repayment }\end{array}$ & 194 & 51 & 52,928 & 22,643 & 25.8 & 42.8 & 0.60 & 0.000 \\
\hline
\end{tabular}

Clearly, the results reported in this commentary do have limitations. We cannot, for example, discern how much the nature of our recruited class is the product of our selection process and how much it is due to students being attracted to our institution by our mission. We also cannot determine how much the results are affected by our being a new school—does "newness" attract a certain type of student? Acquisition bias is also a potential concern for the study. While the response rates for our classes are always excellent (>95\%), the response rates for the nation as a whole are lower, around $63 \%$. However, this is an unlikely source of the observed differences: $63 \%$ is generally considered an acceptable response rate for a survey [7]. Furthermore, it is unlikely that applicants who prioritize leadership are less likely to fulfill a professional expectation such as filling in a AMC survey. Hence, while we recognize potential limitations of the study, we believe we have strong preliminary data supporting the continued use and investigation of our admissions process.

In future research, we will assess the value of the components of the admissions program from the perspective of the school and the faculty. Therefore, we will test whether performance in novel components of our process (the video interview and the group task) predicts the students' performance in our medical school. While we will test the capacity of our assessments to predict academic performance, of greater interest will be the capacity of our innovations to predict students
Fig. 2 Percent of respondents prioritizing each motivation as "essential" over the course of the four years of the study

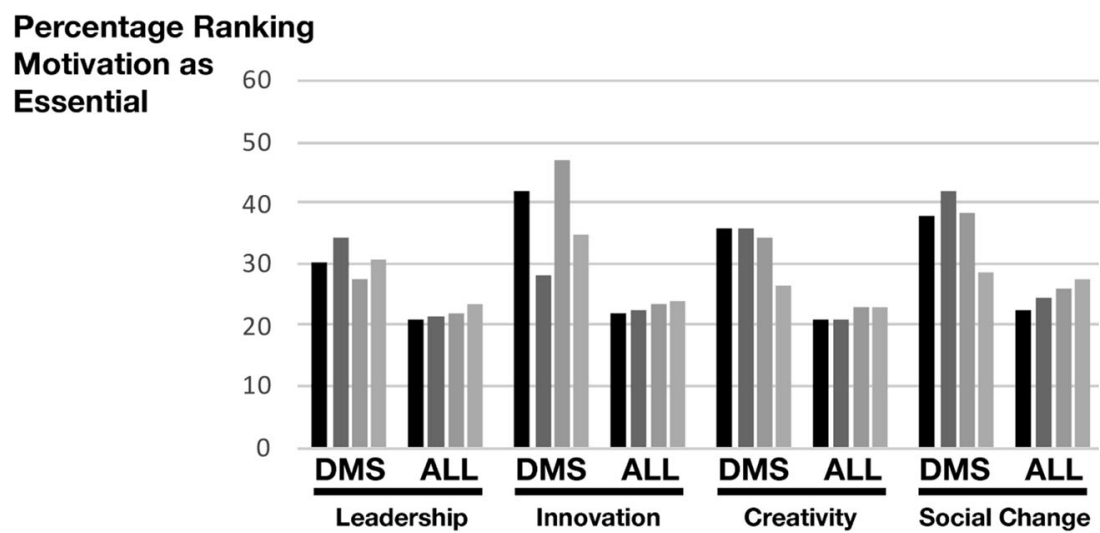

Legend

2016
2018 
displaying aptitude in communication skills, teamwork skills, and leadership.

We will also test the degree to which student ranking by the ASC is influenced by each of the major components of the process (academic evaluations, application-review scores, and student performance in each of the video interviews, the classical interviews, the group task, and in MMI).

A significant question around our innovations is their generalizability. Therefore, we have engaged with other medical schools in the Kern National Transformation Network to assess the transferability of the group task. Several schools within the network have instituted pilot programs to test the group task as part of their admissions programs. Results of the collaborative research will be released as they become available.

This commentary provides an initial description of our innovations in holistic admissions and an overview of our process. It further describes initial outcomes indicating that we have achieved one of our goals: that we have recruited matriculants who value the core components of our mission. In future reports, we will provide more details of our process, and outcomes that test its efficacy outside of the realm of student self-assessment. However, we believed an initial report in the form of a commentary was timely considering both the current efforts to move to holistic admissions processes and the effects of the COVID-19 pandemic upon normal admissions procedures.

Acknowledgments The authors would like to thank all of our many community members who have engaged in reviewing applications and rating applicants. We would also like to thank our colleagues in the Kern National Network for Caring and Character in Medicine for valuable interactions.

Authors' Contributions The admissions innovations were devised by SRS and JD. All three were directly involved in administering the admissions program from 2016 to 2019. The data analysis and initial article writing were performed by ADB. All three authors contributed to editing the article, and reviewed the final version.

Funding Funding for work noted in this manuscript was provided by the Robert D. and Patricia E. Kern family and Kern Family Foundation.
Data Availability Data used is available on the following figshare link: https://figshare.com/articles/dataset/dms_data_msq_xlsx/12354692.

Compliance with Ethical Standards The authors have complied with ethical standards, with no conflicts of interest, and no requirement for IRB review given the nature of the data.

Conflict of Interest The authors declare that they have no conflict of interest.

Ethics Approval We were informed by our Institutional Review Board that there was no need for review as the data was transferred to the authors in aggregated, de-identified form that could not be re-identified by the authors.

Consent to Participate N/A

Consent for Publication We received permission to use the survey data from the American Association of Medical Colleges (AAMC). All authors have approved the manuscript.

Code Availability N/A

\section{References}

1. Conrad SS, Addams AN, Young GH. Holistic review in medical school admissions and selection: a strategic, mission-driven response to shifting societal needs. Acad Med. 2016;91:1472-4.

2. Johnston SC. Anticipating and training the physician of the future: the importance of caring in an age of artificial intelligence. Acad Med. 2018;93:1105-6.

3. Emmett RI. A descriptive analysis of medical school application forms. Acad Med. 1993;68:564-9.

4. Elks ML, Herbert-Carter J, Smith M, Klement B, Knight BB, Anachebe NF. Shifting the curve: fostering academic success in a diverse student body. Acad Med. 2018;93:66-70.

5. Eva KW, Rosenfeld J, Reiter HI, Norman GR. An admissions OSCE: the multiple mini-interview. Med Educ. 2004;38:314-26.

6. Eva KW, Macala C, Fleming B. Twelve tips for constructing a multiple mini-interview. Med Teach. 2019;41:510-6.

7. Baruch Y. Response rate in academic studies: a comparative analysis. Human Relations. 1999;52:421-38.

Publisher's Note Springer Nature remains neutral with regard to jurisdictional claims in published maps and institutional affiliations. 